\title{
Desserts sales forecast based on the new information improved gray model
}

\author{
Di Liang ${ }^{1, a}$, Guizhi Sun ${ }^{1, b}$,Shuang $\mathrm{Wu}^{1, \mathrm{c}}$ \\ ${ }^{1}$ School of Mechanical Engineering, Shenyang University, Shenyang, Liaoning Province, China \\ asydxld@163.com, bsungz1992@163.com, c445391942@qq.com
}

Keywords: Grey system; new information improved model; sales forecast

\begin{abstract}
In this paper, it took a well-known dessert stores as the research object. It analyzed the sales data of the certain selling desserts in the past few months. It took into account that the gray prediction model had some characteristics, such as the less data required, more accurate forecasting, high accuracy. It used the new information improved GM $(1,1)$ model to forecast the raw material of a certain selling dessert under the new information principle of gray system theory. It can order accurately in the next according to the predicted results. It can solve the problem that the waste because of excessive order quantity and the loss because of lacking order quantity.So it can improve the store's turnover and bring more economic benefits.
\end{abstract}

\section{Introduction}

M dessert is a well-known domestic brands, and it is popular with consumers. This paper is studied in a business district branch, The store has high traffic and good sales performance. The inaccurate order will affect the store turnover and reduce profit.

Gray system theory was born in the early 1980s, It is founded by professor Deng Julong. He is a Chinese scholar. It takes the "small sample", "poor information" uncertain system as the research object. It mainly extracts valuable information through generating and developing the "partial" information to achieve correctly describe and effective control of the system operating rule [1-3]. Gray system theory not only establishes a relatively complete theoretical system, but also be applied in many areas, such as agriculture, geology, economics, management, health care, education and so on.So it has won the attention and recognition of domestic and foreign academic[4]. Zhang Qiang proposed the modeling approach combined the new information GM $(1,1)$ model and the weights generated the background value. It used optimization method to realize the adaptive selection of the gray model dimension and background values of weights [5].

In this paper, the new information improved GM $(1,1)$ model is used to predict the order quantity of a kind of material according to the actual store sales and the sales data in recent weeks. It solve the problem that order quantity is inaccuracy. It is found that the predicted result of improved model is more accurate.

\section{Gray GM (1,1) model}

Gray system theory focuses on "small sample", "poor information" uncertainty problems that probability and statistics, fuzzy mathematics are difficult to solve . It explores the movement of things reality rule from operator sequence according to the covered information. Its characteristic is "less data modeling."

GM $(1,1)$ model is a model of an approximate differential and differential equations, it has differential, differential, index compatibility and other properties. the parameters of the model is adjustable, the structure varies over time. It breaks the limits that the general modelings require much more data, it is a new breakthrough ideas and methods on modeling.

Set up $X^{(0)}=\left(x^{(0)}(1), x^{(0)}(2), \cdots x^{(0)}(n)\right), X^{(1)}=\left(x^{(1)}(1), \quad x^{(1)}(2), \cdots, \quad x^{(1)}(\mathrm{n})\right)$,

It calls that the 


$$
\mathrm{x}^{(0)}(\mathrm{k})+\mathrm{ax}{ }^{(1)}(\mathrm{k})=\mathrm{b}
$$

as original form of GM $(1,1)$ model.

Set $X^{(0)}, X^{(1)}$ as shown in Equation, $Z^{(1)}=\left(z^{(1)}(2), z^{(1)}(3), \cdots, z^{(1)}(n)\right)$, among them $\mathrm{z}^{(1)}(\mathrm{k})=\frac{1}{2}\left(\mathrm{x}^{(1)}(\mathrm{k})+\mathrm{x}^{(1)}(\mathrm{k}-1)\right), \mathrm{k}=2,3, \cdots, \mathrm{n}$, it calls that the

$$
\mathrm{x}^{(0)}(k)+a z^{(1)}(k)=b
$$

as basic form of GM $(1,1)$ model.

Set $\mathrm{X}^{(0)}$ as non-negative sequence:

$$
X^{(0)}=\left(\mathrm{x}^{(0)}(1), x^{(0)}(2), \cdots, x^{(0)}(n)\right)
$$

among them $x^{(0)}(k) \geq 0, k=1,2, \cdots, n$; $\mathrm{X}(1)$ is the 1-AGO sequence of $\mathrm{X}(0)$ :

$$
X^{(1)}=\left(\mathrm{x}^{(1)}(1), x^{(1)}(2), \cdots, x^{(1)}(n)\right)
$$

among them $x^{(1)}(k)=\sum_{i=1}^{k} x^{(0)}(i), k=1,2, \cdots, n ; \mathrm{Z}(1)$ is the adjacent mean generated sequence of $\mathrm{X}$ (1),

$$
Z^{(1)}=\left(z^{(1)}(2), z^{(1)}(3), \cdots, z^{(1)}(n)\right)
$$

among them $z^{(1)}(k)=0.5\left(x^{(1)}(k)+x^{(1)}(k-1)\right), k=2,3, \cdots, n_{\circ}$. If $\hat{\mathrm{a}}=[\mathrm{a}, \mathrm{b}]^{T}$ is a parameter,

$$
Y=\left(\begin{array}{c}
x^{(0)}(2) \\
x^{(0)}(3) \\
\vdots \\
x^{(0)}(n)
\end{array}\right), B=\left(\begin{array}{cc}
-z^{(1)}(2) & 1 \\
-z^{(1)}(3) & 1 \\
\vdots & \vdots \\
-z^{(1)}(n) & 1
\end{array}\right)
$$

Then the least squares estimation parameters column of GM $(1,1)$ model meet to:

$$
\hat{a}=\left(B^{T} B\right)^{-1} B^{T} Y
$$

\section{The new information GM $(1,1)$ model and improvement}

The role of new information to awareness is greater than the old information. "The new information priority principle" is the information concept of gray system theory. It can improve the effectiveness of gray model, gray prediction, gray analysis, gray evaluation and gray decision-making to give new information greater weight. "Metabolism" model reflects the " priority principle of new information." The adding of new information provides a scientific basis for the gray element albino. "The new information priority principle" is a concrete manifestation of information timeliness .

According to the new information priority principle of gray system theory, it uses the means that the system itself supplies latest information and improves the boundary conditions to improve the GM model, so the prediction accuracy of the model can be improved.

Set $x^{(0)}=\left(x^{(0)}(1), x^{(0)}(2), \cdots, x^{(0)}(n-1), x^{(0)}(n)\right)$ as the latest information system of system. It has more valuable to study the behavior features because because it is the closest to prediction time. To take full advantage of the new information, set $x^{(0)}(n)$ to $x^{(0)}$,so $x_{1}^{(0)}=x^{(0)} \cup\left\{x^{(0)}(n)\right\}$. It is commonly called new information GM $(1,1)$ model that $x_{1}^{(0)}$ established by the GM $(1,1)$ model .In the GM $(1,1)$ 
model, the boundary conditions is $\hat{x}^{(1)}(1)=x^{(1)}(1)$, and $x^{(1)}(1)=x^{(0)}(1)$, parameters and predictive values $\hat{x}^{(0)}(k)$ are independent of $x^{(0)}(1)$. The initial value $x^{(0)}(1)$ and future value of the predicted value are far apart in time, the impact on the prediction is weak. It is not appropriate that make value as the boundary value. It can be considered that make the conditions that contain the latest information on the system as a boundary condition: $\hat{x}^{(1)}(n)=x^{(1)}(n)$, call parameters of GM $(1,1)$ of $x^{(0)} \mathrm{a}, \mathrm{b}$, the model is:

$$
\begin{gathered}
\qquad\left\{\begin{array}{l}
x^{(0)}(k)+a z^{(1)}(k)=b, k=2,3, \cdots, n-1, \\
\hat{x}^{(1)}(1)=x^{(1)}(1) .
\end{array}\right. \\
\text { Call }\left\{\begin{array}{l}
x^{(0)}(k)+a z^{(1)}(k)=b_{1}, k=2,3, \cdots, n, \\
\hat{x}^{(1)}(n)=x^{(1)}(n)
\end{array}\right. \text { as the new information GM (1,1) model. The }
\end{gathered}
$$
parameter estimation of the model is :

$$
\begin{gathered}
a_{1}=\frac{1}{\left|D_{1}\right|} \sum_{k=2}^{n} x^{(0)}(k)\left[\beta_{1}-(n-1) z^{(1)}(k)\right], \\
b_{1}=\frac{1}{\left|D_{1}\right|} \sum_{k=2}^{n} x^{(0)}(k)\left[\alpha_{1}-z^{(1)}(k) \beta_{1}\right],
\end{gathered}
$$

Among them $\alpha_{1}=\sum_{k=2}^{n}\left(z^{(1)}(k)\right)^{2}, \beta_{1}=\sum_{k=2}^{n} z^{(1)}(k),\left|D_{1}\right|=(n-1) \alpha_{1}-\beta_{1}^{2}$.

\section{Practical problems study}

The turnover of $\mathrm{M}$ dessert have a great relationship with climate, summer business is the best, some desserts raw materials is shown in Table 1.

Table 1 A dessert raw material scale

\begin{tabular}{ccccc}
\hline Date (march to may) & $30-5$ & $6-12$ & $13-19$ & $20-29$ \\
\hline Week number & 1 & 2 & 3 & 4 \\
\hline consumption $(\mathrm{kg})$ & 2.874 & 3.278 & 3.337 & 3.39 \\
\hline
\end{tabular}

The original data is $x^{(0)}=(2.874,3.278,3.337,3.39)$, the new information is $x^{(0)}(5)=3.3679$, establish GM $(1,1)$ model for $x^{(0)}$, the model parameters is:

$$
\mathrm{a}=-0.0372, \quad \mathrm{~b}=-3.0654
$$

Substitute to $x_{1}^{(0)}=x^{(0)} \cup\left\{x^{(0)}(5)\right\}$, The parameters of the new information GM $(1,1)$ model and the new information improvement GM $(1,1)$ model are:

$$
a=-0.0429, \quad b=3.02
$$

Predictive value and error of the three models are shown in Table 2. 
Table 2 Predictive value and error of the three models

\begin{tabular}{|c|c|c|c|c|c|c|c|}
\hline \multirow[t]{2}{*}{$\mathrm{k}$} & \multirow[t]{2}{*}{$x^{(0)}(k)$} & \multicolumn{2}{|c|}{ GM(1,1) } & \multicolumn{2}{|c|}{$\begin{array}{l}\text { New information } \\
\text { GM }(1,1) \text { model }\end{array}$} & \multicolumn{2}{|c|}{$\begin{array}{l}\text { New information improvement } \\
\text { GM }(1,1) \text { model }\end{array}$} \\
\hline & & $\hat{x}^{(0)}(k)$ & error $/ \%$ & $\hat{x}^{(0)}(k)$ & error/\% & $\hat{x}^{(0)}(k)$ & error/\% \\
\hline 1 & 2.874 & 2.874 & 0 & 2.874 & 0 & 2.874 & 0 \\
\hline 2 & 3.278 & 3.236 & 1.422 & 3.211 & 2.044 & 3.2119 & 2.013 \\
\hline 3 & 3.337 & $\begin{array}{c}3.354 \\
5\end{array}$ & 0.524 & 3.3526 & 0.467 & 3.3526 & 0.467 \\
\hline 4 & 3.39 & $\begin{array}{c}3.481 \\
7\end{array}$ & 2.705 & 3.4995 & 3.23 & 3.4996 & 3.232 \\
\hline 5 & 3.3679 & $\begin{array}{c}3.613 \\
6\end{array}$ & 1.778 & 3.653 & 0.707 & 3.653 & 0.707 \\
\hline \multicolumn{2}{|c|}{ original error/\% } & \multicolumn{2}{|c|}{1.778} & \multicolumn{2}{|c|}{0.707} & \multicolumn{2}{|c|}{0.707} \\
\hline \multicolumn{2}{|c|}{ average error/\% } & \multicolumn{2}{|c|}{1.607} & \multicolumn{2}{|c|}{1.612} & \multicolumn{2}{|c|}{1.605} \\
\hline
\end{tabular}

The above table shows that the original error and average error of new information improvement GM $(1,1)$ model is lower than the other two models, and the error is minimal, the accuracy is the highest. Therefore, use the new information improvement GM $(1,1)$ model to predict the amount of raw materials for the dessert next week, the result is 3.85 .

\section{Summary}

The new information improvement of gray theory is used to predict the amount of raw materials of a dessert combined with its actual orders and the way to operate by the research of $\mathrm{M}$ dessert actual situation, The order accuracy is increased greatly, it can avoid to impact the turnover because of stockout and cause a loss because of residue.

\section{References}

[1] J.L. Deng: Gray Theoretical Basis (Huazhong University of Science and Technology Press, China 2002) (In Chines)

[2] J.L. Deng: Gray Theoretical Basic Approach (Huazhong University of Science and Technology Press, China 2004) (In Chines)

[3] S.F.Liu,Y.G.Dang,Z.G.Fang: The Grey System Theory and it's Application (Science Press, China 2004) (In Chines)

[4] L.Z. Cui: Grey prediction technology and its application research (Ph.D.,Nanjing University of Aeronautics and Astronautics, China 2010), p,13-17 (In Chines)

[5] Q.Zhang,H.X.Wen: Journal of Shaanxi University of Science \& Technology Vol. 26(2008), p. 104-116 (In Chines) 